\title{
Do Messianismo Populista à Distopia Contemporânea: os tortuosos percursos da modernidade literária brasileira na segunda metade do século $x x$
}

\section{Luciana Murari ${ }^{\mathrm{I}}$}

ARAÚJO, Homero Vizeu. Futuro Pifado na Literatura Brasileira: Promessas Desenvolvimentistas e Modernização Autoritária. Porto Alegre, UFRGS, 20I4, 284 p.

O teatro de Nelson Rodrigues e o de Chico Buarque, a poesia de Carlos Drummond de Andrade, a de Cecília Meirelles e a de João Cabral de Melo Neto, a canção de Caetano Veloso, o romance de Carlos Heitor Cony e o de João Guimarães Rosa, entre outras criações da moderna cultura brasileira, inspiram as leituras de Homero Vizeu Araújo em Futuro Pifado na Literatura Brasileira. A coletânea, formada por ensaios e artigos autônomos, parece especialmente heterogênea à primeira vista, mas o subtítulo define o escopo da grande maioria dos artigos e ensaios nela reunidos: Promessas Desenvolvimentistas e Modernização Autoritária.

Ao fim e ao cabo, a soma das partes mostra-se maior que o todo, já que o livro nos permite acompanhar uma reflexão amadurecida sobre a experiência histórica singular da sociedade brasileira da segunda metade do século XX em diante. A diversidade dos temas deste Futuro Pifado multiplica, para além dos estudos sobre cada um dos autores e obras percorridos ao longo do livro, a percepção dos impasses vividos pela intelectualidade local, entre a utopia e a frustração. O livro testemunha como, em países como o Brasil, a modernidade - não apenas como experiência objetiva, mas também como imagem, espectro, desejo - fez-se acompanhar de perto pelo seu contrário, produzindo a experiência periférica de um cruzamento de temporalidades que não chegou a produzir qualquer síntese coerente.

I Professora do Departamento de História da Pontifícia Universidade Católica do Rio Grande do Sul (PUCRS, Porto Alegre, RS, Brasil). Mestre em História pela Universidade Federal de Minas Gerais (UFMG) e doutora em História Social pela Universidade de São Paulo (USP). Bolsista de Produtividade em Pesquisa do CNPq - Nível 2.

E-mail: lmurari@hotmail.com. 
Compreende-se, assim, que estranhamento e perplexidade acompanhem esse amplo painel da criação cultural brasileira. Futuro Pifado aborda simultaneamente o produto da literatura, sua ratio subjacente e seu diálogo com a sociedade, levando em conta a missão autoinstituída pelos intelectuais, ao menos, desde a Independência do país: pretensamente dotados dos instrumentos necessários para o conhecimento da realidade, caberia a eles aplicá-los aos problemas locais específicos e, a partir daí, fazer um diagnóstico que permitiria combater os males nacionais, conduzindo uma sociedade "atrasada", aos poucos, em direção à necessária atualização civilizatória. Manifestações diversas dessa crença sucederam-se a partir, pelo menos, do trabalho dos intelectuais reformistas do Império, passando em seguida da interpretação científica de raiz determinista às formas difusas de culturalismo e de perquirição identitária representadas pelo ensaísmo modernista, pelo discurso jurídico, pela sociologia interpretativa, pelo emprego do método histórico-estrutural, da historiografia econômica e da antropologia.

A literatura acompanhou de perto esse movimento, como campo privilegiado da criação cultural em que a observação da realidade colava-se à ficção para desempenhar seu papel como forma de conhecimento da totalidade nacional e de difusão de ideias e projetos. Obras literárias ficcionais modelaram as formas de ver o mundo que disputavam espaço entre os intelectuais, desde o princípio cindidos em torno de visões diversas do povo, objeto indeterminado sobre o qual falavam. Nem sempre, entretanto, este era considerado sujeito ativo na construção da história e, em um país de tradição autoritária, nem sempre era tido como apto a exercer algum protagonismo social. O passado escravocrata, a concentração da propriedade de terras e a espantosa desigualdade social (e educacional) alimentaram uma insatisfação mais ou menos difusa que favoreceu análises críticas da realidade do país, e gerou projetos que durante algumas décadas acreditaram-se de fato capaz de mudar a realidade. Desde o Romantismo e até décadas recentes, a literatura brasileira buscou ser documento e consciência.

O marco zero dos estudos reunidos em Futuro Pifado é uma das últimas manifestações dos intelectuais brasileiros em busca de relevância social e autolegitimação. Forma específica de messianismo social, o desenvolvimentismo foi um projeto de construção de um Brasil moderno que, com graus diversos de apelo à retórica nacionalista, alimentava sonhos redentores de sincronização da realidade brasileira com as sociedades ditas "avançadas". Fazendo um balanço das últimas décadas do século XX, fica constatado que a utopia desenvolvimentista difundida a partir dos anos I950 não logrou criar um país “desenvolvido", nem tampouco garantiu uma sociedade democrática, com a ascensão do regime de exceção no período pós-I968. Nos ensaios de Araújo, acompanhamos a tomada de consciência a respeito do fracasso dos intelectuais em alguns dos momentos mais críticos da história do país.

Ao falar de um contemporâneo particularmente brilhante na vida cultural brasileira, mas ainda carente de interpretações amplas o suficiente para abarcar suas contradições, Araújo dialoga com dois grandes interlocutores, Antonio Candido e Roberto Schwarz, mestres de uma nova tradição crítica em que o compromisso com o tratamento da linguagem literária não se descola da análise histórica e sociológica. 
Os dois autores são a referência para pensar a literatura para além do compromisso institucional com as fronteiras burocráticas do meio acadêmico, ao constituírem um discurso em que ela é devolvida aos campos da experiência e da cultura, que comportam não apenas aspectos sociais, mas a própria consciência da linguagem literária, ela também um dado, podemos dizer, contextual. Observada para além de si mesma, a atividade intelectual ganha em poder de reflexão e em capacidade crítica.

Nesse sentido, um dos textos mais vigorosos do Futuro Pifado é o texto de abertura, "Notas sobre 'A Nova Narrativa', de Antonio Candido: Experimentalismo na Narrativa e Impasses do Narrador Romanesco sob o Regime Autoritário", uma reflexão circunstanciada sobre o ensaio do estudioso, datado de I979 e publicado em A Educação pela Noite. Ao comentar o texto, o autor põe em revista alguns de seus procedimentos fundamentais, entre eles a criação de um eixo interpretativo capaz de cruzar a heterogeneidade da produção cultural brasileira e, sem deixar de considerá-la, atentar para a expressão literária a partir das inflexões do momento histórico - compreendido não como conjuntura factual, mas como a vigência de uma dada sensibilidade em relação à existência brasileira no tempo. Dessa maneira, o autor define com precisão, por exemplo, a lógica por trás da perda da pretensão totalizante do projeto desenvolvimentista, em continuidade com a crítica literária acadêmica: "Tal deleite com a autonomia da esfera literária é ele mesmo datado historicamente e já foi notado o quanto a importação do desconstrucionismo coincidiu com a desconstrução do país" (p. 28).

Essa abordagem do estudo de Candido conduz Araújo à análise do ponto de vista dos personagens e de sua perspectiva de futuro, que dialoga com diferentes contextos da literatura brasileira do período desenvolvimentista. $\mathrm{O}$ autor define a voz narrativa do romance dos anos 1970 como "primeira pessoa catastrófica", diálogo implícito com o clássico artigo "Literatura e Subdesenvolvimento". Naquele caso, Candido havia definido a literatura brasileira do período pré-I930 como manifestação de uma "consciência amena do atraso", em contraposição ao período seguinte, que expressaria uma "consciência catastrófica do atraso". O cerne da discussão de Araújo passa a ser as implicações de uma "primeira pessoa catastrófica" quando contraposta à "terceira pessoa catastrófica" do desenvolvimentismo, ou seja, a incapacidade de observar a realidade em perspectiva, distinguindo o sujeito do objeto da narração, sintoma do caráter iníquo da modernização e da própria inutilidade dos bem intencionados esforços conciliatórios do período anterior, além, é claro, do próprio sentimento de exclusão do intelectual da esfera pública.

A homenagem desse Futuro Pifado à obra de Candido faz-se, assim, através da continuidade dos debates que ela suscita, o que também se observa em relação aos estudos de Roberto Schwarz, ao qual vários ensaios prestam tributo, mantendo viva sua escrita ao sugerir novas leituras possíveis, à luz de novos dados, insights e polêmicas. Em particular, o ensaio "O Pai de Família e Aquela Coisa de Sempre" apresenta uma ótima observação em perspectiva do trabalho do crítico, definido em poucas e incisivas palavras: "Ele está sempre disposto a desencavar pontos de continuidade e de ruptura na cultura brasileira na sua conexão desigual e combinada com o andamento mundial do capitalismo desvairado e devastador" (p. I28). A crítica acadêmica brasileira só tem a ganhar com essa contínua retomada de sua própria herança, sobretudo porque, como demonstra o autor em sua leitura de Schwarz, a sensibilidade do crítico permite 
discutir o passado ao mesmo tempo que lança luzes à compreensão de tendências que apontam para o futuro.

Podemos dizer que o Futuro Pifado evidencia que a crítica literária brasileira experimenta ela mesma a influência de uma "causalidade interna", outro conceito desenvolvido por Candido em "Literatura e Subdesenvolvimento", retomado por Araújo no ensaio sobre o teatro dos anos I970. Ou seja, em direção ao que seria uma "superação da dependência", a cultura brasileira criou modelos críticos nacionais que alimentaram o debate interno e que tornaram possível, aliás, fazer um uso mais consciente e aprofundado das referências externas. $\mathrm{O}$ trabalho crítico de Candido inaugurou uma espécie de "causalidade interna" para os estudos literários brasileiros, abrindo uma trilha que convida a um entendimento da literatura também em sua dinâmica sociológica. Dessa maneira, força-nos a uma percepção do intelectual como uma subjetividade criativa em diálogo com seu tempo e que se expressa igualmente através do que ele silencia, daquilo que o perturba, e, além disso, de uma contínua prestação de contas com sua própria trajetória.

Ficam demonstradas, assim, a fertilidade da "nova tradição crítica" formada a partir de Candido e Schwarz e sua renovação, não apenas pela amplitude e pelo longo alcance da abordagem de Araújo, mas também por sua escrita desabusada, que não foge do diálogo com os avatares da sabedoria acadêmica, e trata de convertê-lo a uma linguagem contemporânea, corrente e desarmada. Pondo em prática o debate teórico, o autor enfrenta a encrenca que criou para si mesmo e organiza a bagunça dos intelectuais com humor modernista-tropicalista (o ator Geraldo Del Rey era "galã para cabocla nenhuma botar defeito"; Nelson Rodrigues tinha fama de "taradão do teatro nacional"; a esquerda "ficou tiririca" com Cony). Em outros momentos, Araújo demonstra uma criatividade propriamente literária, fazendo referência, por exemplo, a "cadáveres ressecados e expostos à umidade inexistente". Ou, ainda, faz uso generoso de saborosas tiradas irônicas, considerando, por exemplo, a respeito da obra de Paulo Lins, que "Escrever prosa ruim deixou de ser privilégio de classe, o que pode ser saudado como algum tipo de evolução democrática” (p. I23).

Assim, acompanhando o autor em seus longos voos históricos e seus mergulhos profundos no texto literário, vemos que, depois do desenvolvimentismo festivo dos anos I950 e I960, a "modernização autoritária" expôs a ingenuidade dos intelectuais, exacerbou os contrastes sociais e, antes que tivéssemos encontrado as respostas, o mundo pós-industrial mudou os termos do debate. Desde então, tornaram-se evidentes os dilemas da elite letrada, sobretudo quando se ousava chamar a atenção para a relação ambígua entre o escritor e o público, entre o fazer literário e o projeto nacional. Este já era um problema latente na literatura do desenvolvimentismo. De fato, a imagem do povo é o tema de um dos artigos mais ricos deste Futuro Pifado, uma análise do teatro de Nelson Rodrigues através de sua contraposição com outras peças que colocam em cena a cultura popular: O pagador de Promessas, de Dias Gomes; Auto da Compadecida, de Ariano Suassuna; e Lisbela e o Prisioneiro, de Osman Lins. Trazendo à tona a batalha de Nelson Rodrigues contra o (quase) consenso de esquerda, Araújo expõe a fragilidade dos arranjos conciliatórios de longa tradição na cultura brasileira, abrindo espaço para uma leitura compreensiva da obra do teatrólogo dos subúrbios cariocas, no conjunto da produção dramatúrgica brasileira. 
Esta é a outra face do debate trazido por Araújo, que trata do sentimento de inutilidade dos esforços dos intelectuais, em sua exegese e sua encenação do problema nacional no período pós-I968. No ensaio sobre Gota d'Água, peça de Chico Buarque e Paulo Pontes definida pelo autor, em uma de suas saborosas tiradas, como "uma espécie de missa negra nacional-popular” (p.63), dois clássicos do teatro nacional da era desenvolvimentista - Eles Não Usam Black-tie, de Gianfrancesco Guarnieri, e O Pagador de Promessas - são tomados como pontos de referência para uma releitura da dramaturgia brasileira como um diálogo intertextual promovido pela retomada de temas e pelo emprego de novas soluções dramáticas que mantêm dinâmico o debate. A criação de uma imagem generosa do povo pobre e a possibilidade de sua integração social virtuosa, através de alguma forma de conciliação da modernidade capitalista com a memória cultural brasileira, são então observadas com um olhar descrente em relação à ascensão social e à afirmação de um pacto integrador que aparasse as contradições entre a lógica do capital e a espontaneidade das manifestações populares, que em grande parte tendiam a tornar-se anacrônicas, o que fica claro na análise d’A Ópera do Malandro, de Chico Buarque.

O Futuro Pifado contribui também para fazer um balanço dessa trajetória histórica, pois, ao trazer à tona a cultura brasileira do pós-guerra em diante, expõe um cruzamento vertiginoso de ideias em torno da tradição, da modernidade cosmopolita e da transição (Possível? Desejável?) de uma à outra. Com uma disposição singular para o enfrentamento das contradições inerentes à atividade intelectual em um país pouco letrado, que tem oportunidades limitadas de inserção no mercado de bens culturais, o autor mescla com habilidade as perspectivas da história (dos intelectuais, da literatura, das sensibilidades) e da crítica literária, exercitando a análise propriamente estética do texto em sintonia com a percepção da literatura, simultaneamente, como um exercício de comprometimento, dentro da melhor tradição de Candido e Schwarz.

Acompanhamos, assim, o percurso crítico de Araújo em dois sentidos: para dentro e para fora do texto. Exemplificando através dos ensaios do Futuro Pifado, o percurso para dentro do texto o valoriza como construção poética singular, o que, no caso da análise do Romanceiro da Inconfidência, de Cecília Meireles, manifesta-se no estudo formal do andamento, dos tons e timbres da elocução, das divisões sintáticas das estrofes, da alternância de vozes narrativas, das fórmulas poéticas e da estruturação do verso. No mesmo estudo, olhando para fora do texto, Araújo atenta para o tratamento da matéria histórica - os personagens, a condição colonial, a exploração econômica, o poder da metrópole, o sentido mítico e simbólico do evento. O mais relevante, no entanto, é a integração de tais perspectivas, na observação, por exemplo, do significado do uso da voz narrativa em conformidade com o status social dos personagens.

Do "país do futuro" dos anos do populismo ao presente desprovido de projetos (e até mesmo da crença de que possa existir algum), os textos do livro vão ao fundo na problematização da literatura e do fazer literário, cruzando as coordenadas da linguagem com aquelas do tempo e do lugar. Hoje soa anacrônico falar em conceitos como "subdesenvolvimento" e sua versão suave, o "país em desenvolvimento", imagens que alimentavam uma visão esquemática e evolucionista da realidade. No 
entanto, esse Futuro Pifado ajuda-nos a vencer a distância ideológica e proporciona uma experiência de leitura literária e de percepção histórica: vitoriosos e vencidos de hoje e de ontem, conflito, compromisso e extermínio, obras canônicas ou obscurecidas pelo tempo, grandiosas tragédias e dramas inglórios cruzam-se inopinadamente. As novidades enraízam-se em seus contrários, retrocessos, vacilações e arranjos pouco ortodoxos sucedem-se, conduzidos pela abordagem cuidadosa do autor, que não arrisca a individualidade de cada texto, tampouco perde de vista o nexo entre as ideias e sua expressão.

A tarefa a que se propôs Araújo não é, certamente, das mais fáceis, levando-se em conta que o passado recente pode, às vezes, parecer mais estranho e perturbador do que épocas cronologicamente mais distantes. Ao longo do tempo, consolidamos visões históricas, consagrando interpretações e criando um imaginário em torno de fases, eventos, personagens e um indefinível "espírito do tempo". Construímos, assim, uma memória que permite que o passado possa ser contrastado com o presente e com os "outros passados", e podemos, dessa forma, observá-lo serenamente à distância. É assim que ele pode tornar-se definitivamente passado, o que depende de uma tarefa coletiva de definir o memorável e o esquecível, à luz de uma visão corrente da história (sempre sujeita, no entanto, a novo escrutínio). A memória de um tempo fica, enfim, à nossa disposição, já devidamente filtrada.

Torna-se possível para nós, a partir de então, avaliar a década de I970, por exemplo, época de ressaca das ilusões desenvolvimentistas em que a supremacia esquerdista da intelectualidade combinava-se com seu quase completo alijamento do projeto nacional, frustradas as expectativas gerais de que seria possível arquitetar e construir uma história brasileira em nova chave, em alguma medida popular, socialista, e/ou nacionalista. Muito precariamente digerido pela história cultural brasileira, o pós-I968 foi um tempo de incerteza e de fragmentação. Araújo demonstra, a partir do diálogo com Antonio Candido, como a literatura da época manteve-se em consonância com os processos sociopolíticos, ao perder muito de sua capacidade de observação distanciada do real e de demarcação do espaço entre o sujeito da enunciação e o objeto de seu discurso, o que inibiu a mirada analítica e alimentou visões cínicas e irônicas do real.

Do ponto de vista atual, os anos I970 foram prolíficos em matéria de esquecimentos. Talvez não tenhamos produzido, até hoje, uma síntese que os compreenda em seus próprios termos e nos termos de sua inserção no fluxo cultural brasileiro, tarefa com a qual Futuro Pifado contribui decisivamente. Muitas vezes, aliás, aquele período parece mais lembrado por manifestações massivas bastante típicas e sintomáticas da expansão do mercado de consumo da indústria do entretenimento - a música dita "cafona", a pornochanchada, as novelas de televisão, a publicidade, os escândalos e as tragédias da vida real registrados pelos jornais. O diálogo da literatura com esse real, em que, observado com os olhos da intelectualidade, o futuro imaginado converteu-se em distopia, é uma das características decisivas da cultura daquela década, em contraste com a "fase heroica" anterior, democrática e otimista.

Esquecemo-nos, por exemplo, de Pilatos, romance de Carlos Heitor Cony publicado em I974 que o autor de Futuro Pifado corajosamente desencava, assumindo o risco de enfrentar um livro "desconcertante e assombroso", que acena para a incompreensão 
do leitor e ameaça ser reduzido a mera curiosidade pitoresca pela distância que adquiriu em relação a nosso tempo. $\mathrm{O}$ ensaio de Araújo demonstra que é altamente desejável e produtivo revisitar aquela década e percorrer com novos olhos suas obsessões e excentricidades, restabelecendo sua conexão com a história literária brasileira, através, por exemplo, de analogias férteis, ainda que aparentemente improváveis, com clássicos como Memórias de um Sargento de Milícias, de Manuel Antonio de Almeida, e Quincas Borba, de Machado de Assis. Inscrito no fluxo das ideias em torno das quais se move a intelectualidade durante um período específico da vida brasileira, o romance de Cony ganha outra dimensão e pode ser pensado como um objeto singular que reflete sobre o real histórico e sobre o sentido da própria criação artística.

O tratamento do contemporâneo pede atenção adicional para a multiplicidade de referenciais capazes de refletir os processos de circulação de ideias e de contínua revisão da história do país, de acordo com uma percepção não hierárquica da produção cultural (erudita ou popular, massiva ou artística). Em seu trabalho sobre Grande Sertão: Veredas, por exemplo, o autor do Futuro Pifado conduz a reflexão acadêmica a um diálogo com manifestações tão aparentemente disparatadas como a música de Tom Jobim e o filme Tropa de Elite. Analogias como essas valorizam a literatura simultaneamente como manifestação estética e como discursividade, abrindo perspectivas críticas preciosas como, por exemplo, a leitura dos versos camonianos de Carlos Drummond de Andrade em “A Máquina do Mundo", de Claro Enigma, tidos como manifestação da dialética entre localismo e cosmopolitismo.

O estudo do personagem Riobaldo é também uma eficiente prestação de contas com a história literária brasileira em sua inclinação evolucionista (no sentido da criação de uma literatura nacional), em que o tema da cultura popular, em alta nos tempos do populismo, tem seu significado intrínseco somado ao desejo propriamente modernista (em sentido amplo) de experimentação com a linguagem literária. Nesse caso, os dois planos são combinados e articulados, sob a condição do contraditório, o que se reflete, entre outras constatações, na definição de Riobaldo como uma "aporia viva" (p. 9I), à margem do mundo letrado e da barbárie sertaneja. Este era um tema caro à intelectualidade brasileira desde, pelo menos, Os Sertões, de Euclides da Cunha, inserção realista e literariamente engenhosa dos confins do território na consciência letrada nacional. Em Guimarães Rosa, Araújo lê a conjunção improvável entre arcaísmo e modernidade como uma utopia de síntese entre o espírito nacional e o impulso universalizante.

Outro exercício bem sucedido, nesse esforço de leitura abrangente do movimento cultural brasileiro, são os estudos do autor sobre João Cabral de Melo Neto. Ao mesmo tempo que visita contemporâneos do poeta e verifica outras respostas dadas ao problema do engajamento da literatura e da relação entre obra e público, Araújo enfrenta o problema das "duas águas" da obra cabralina, dividida entre a poesia engajada, que amplia o público ao apelar para a simplicidade das fórmulas arcaicas, e a poesia cerebral e rigorosa, que exige um leitor com sólida formação literária. Nesse estudo, novamente o diálogo com a obra crítica de Roberto Schwarz dá o tom, problematizando o histórico insulamento da intelectualidade brasileira em relação ao público (daí o uso da ideia de "autopúblico", a partir de Antonio Candido), e, no caso 
do pós-I968, a convivência entre um regime de direita e a hegemonia intelectual de esquerda. Ao enfrentar o tema do público, o autor expõe as ambiguidades da vida brasileira do período, marcada pela manutenção de gritantes desigualdades no acesso à educação e por um mercado cultural ainda exíguo e dependente. À luz de manifestações aparentemente díspares como o teatro de Nelson Rodrigues, a bossa nova e o concretismo, o crítico apresenta a poesia irônica de João Cabral no contexto da realização e da frustração do desejo de modernidade na periferia capitalista.

No mesmo tom, a poesia de Claro Enigma, de Carlos Drummond de Andrade, é confrontada com as ambiguidades do sistema literário brasileiro, especialmente com a percepção de que o papel da literatura no projeto de modernidade esboçado a partir dos anos 1950 estava condenado a ser ínfimo. Viam-se frustradas as expectativas de formação de um público leitor amplo, em meio à especialização literária e à "concorrência" do mercado cultural massivo, num país em grande parte ainda analfabeto e praticamente insulado em termos linguísticos. Os poemas de Claro Enigma são, assim, lidos como produtos da combinação entre sofisticação formal, liberdade criativa e sentimento de irrelevância, alimentando uma escrita ressentida e tensa, dirigida a uma sociedade que se moderniza e que, sem enfrentar alguns de seus maiores dramas, vê-se lançada às tentações do consumo. Intimismo e melancolia marcam uma mirada conflituosa e desiludida do mundo e de si mesmo pelo poeta lírico, que apela ao sarcasmo como subterfúgio.

À contramão da tendência de investir na costumeira divisão do trabalho intelectual, que convida à especialização e restringe o exercício analítico a estudos de caso que se ocupam da descrição de uma obra em seus procedimentos formais, o que lemos em Futuro Pifado é uma arrojada interpretação histórica, capaz, ao mesmo tempo, de conferir significado a esses procedimentos. A visão sintética faculta ao autor a intercessão de escritores, obras, temáticas, contextos, sem perder de vista a especificidade, através de um movimento dialético entre o macro e o micro, reproduzido em diversos planos combinados: dentro de uma mesma obra, na obra de um autor, entre obras de diferentes autores, em direção a análises diacrônicas e sincrônicas da história intelectual brasileira. Chegamos ao fim das páginas desse Futuro Pifado com a sensação de que esse é um esforço a ser compartilhado pelos pesquisadores que se ocupam da literatura brasileira e se interessam pela produção de uma crítica literária vibrante, desprovida de preceitos disciplinares e dispensada de autojustificação.

DoI: http://dx.doi.org/Io.II606/issn.23I6-90IX.voi6opI90-I97 